\title{
Resveratrol counteracts lipopolysaccharide-induced depressive- like behaviors via enhanced hippocampal neurogenesis
}

\author{
Liang Liu ${ }^{1,2}$, Qin Zhang ${ }^{1}$, Yulong Cai ${ }^{1}$, Dayu Sun ${ }^{1,2}, \mathrm{Xie} \mathrm{He}^{1}$, Lian Wang ${ }^{1}$, Dan Yu ${ }^{1}$, \\ Xin $\mathrm{Li}^{1}$, Xiaoyi Xiong ${ }^{2}$, Haiwei $\mathrm{Xu}^{3}$, Qingwu Yang ${ }^{2}$ and Xiaotang Fan ${ }^{1}$ \\ ${ }^{1}$ Department of Developmental Neuropsychology, School of Psychology, Third Military Medical University, Chongqing, China \\ 2 Department of Neurology, Xinqiao Hospital, Third Military Medical University, Chongqing, China \\ ${ }^{3}$ Southwest Eye Hospital, Southwest Hospital, Third Military Medical University, Chongqing, PR China \\ Correspondence to: Xiaotang Fan, email: fanxiaotang2005@163.com \\ Qingwu Yang, email: yangqwmlys@163.com \\ Keywords: resveratrol; depression; neurogenesis; LPS; radial glial cells; Pathology Section \\ Received: May 26, $2016 \quad$ Accepted: July 20, $2016 \quad$ Published: August 10, 2016
}

\section{ABSTRACT}

Radial glial-like cells (RGLs) in the adult dentate gyrus (DG) function as progenitor cells for adult hippocampal neurogenesis, a process involved in the stress-related pathophysiology and treatment efficiency of depression. Resveratrol (RSV) has been demonstrated to be a potent activator of neurogenesis. The present study investigated whether chronic RSV treatment has antidepressant potential in relation to hippocampal neurogenesis. Mice received two weeks of RSV $(20 \mathrm{mg} /$ kg) or dimethylsulfoxide (DMSO) treatment, followed by lipopolysaccharide (LPS; 1 $\mathrm{mg} / \mathrm{kg}$ ) or saline injections for 5 days. We found that RSV treatment abrogated the increased immobility in the forced swimming test and tail suspension test induced by LPS. Immunohistochemical staining revealed that RSV treatment reversed the increase in microglial activation and the inhibition in DG neurogenesis. RSV treatment also attenuated LPS-induced defects in the expanding of RGLs through promoting symmetric division. In addition, RSV ameliorated LPS-induced NF-KB activation in the hippocampus coincides with the up-regulation levels of Sirt1 and Hes1. Taken together, these data indicated that RSV-induced Sirt1 activation counteracts LPSinduced depression-like behaviors via a neurogenic mechanism. A new model to understand the role of RSV in treating depression may result from these findings.

\section{INTRODUCTION}

Depression is a chronic, recurring, and lifethreatening mood disorder, which affects more than 14 percent of the population and imposes a tremendous burden on both individuals and society [1]. Clinically, depression is characterized by anhedonia, sleep disturbances, reduced food intake, decreased locomotor activity, and increased sensitivity to pain [2]. The etiology of depression has not been fully elucidated and the biological mechanisms remain unclear [3].

Adult hippocampal neurogenesis in the subgranular zone (SGZ) of the DG contributes to mood regulation [4]. Brain imaging and postmortem studies of patients suggest that reduced DG size may be related to decreased neurogenesis and mature neuronal cell loss [5]. Impaired hippocampal neurogenesis also occurs in some rodent and non-human primate models of depression such as repeat restraint stress, chronic unpredictable mild stress, social defeat stress, social isolation, and LPS or corticosterone administration [6-8]. A recent study by Fava et al. found that a novel neurogenic compound, NSI-189, effectively treated major depressive disorder [9]. Thus, these findings indicated that reduced adult hippocampal neurogenesis may be involved in the pathological mechanisms of depression and that up-regulating neurogenesis is a potential therapeutic target for treating depression.

The neural stem cells (NSCs) in the SGZ are classified into types 1 and 2 . Type 1 cells have a radial glia-like (RGL) morphology and express both glial fibrillary acidic protein (GFAP) and SOX2; type 2 cells express only $\mathrm{SOX} 2$, and can function as the precursor cells to neurons or astrocytes $[10,11]$. Several lines of evidence have demonstrated that the GFAP-expressing 
RGLs determine the type of NSCs in postnatal and adult brain, and provide the principal source of constitutive neurogenesis in the adult hippocampus by increasing their capability for proliferation and/or survival in response to stimuli and environmental demands [12, 13]. However, the mechanisms to maintain the neurogenesis capacity of these RGLs in response to stress have not been fully elucidated.

Resveratrol (RSV) is a stilbene compound that is found in the skin of red grapes and in certain medicinal plants $[14,15]$. Recently, RSV was reported to promote the survival of adult hippocampal NSCs in a mouse model of neuroinflammation [16]. Similarly, our previous study confirmed that RSV activation of Sirtuin type 1 (Sirt1) blocked the decline of hippocampal neurogenesis induced by ethanol exposure during early postnatal life [17]. Indeed, RSV alone increased proliferation of RGLs in the postnatal SGZ [18]. Moreover, recent studies have found that RSV ameliorated depressive-like behaviors in animal models [19-21]. The role of RSV in promoting hippocampal neurogenesis, including potential antidepressant-like properties, has not been investigated.

In the present study, an LPS induced stress-based depressive mouse model $[6,22,23]$ was used to test the antidepressant effects of RSV. Our findings revealed that pretreatment with RSV for 2 weeks reversed LPS-induced depression-like behaviors. The antidepressant effects of RSV coincide with reduced LPS-induced inflammation and inhibition of hippocampal neurogenesis. Furthermore, we present the first demonstration that RSV activation of Sirt1 reverses the LPS-induced reductions in the number

(A)

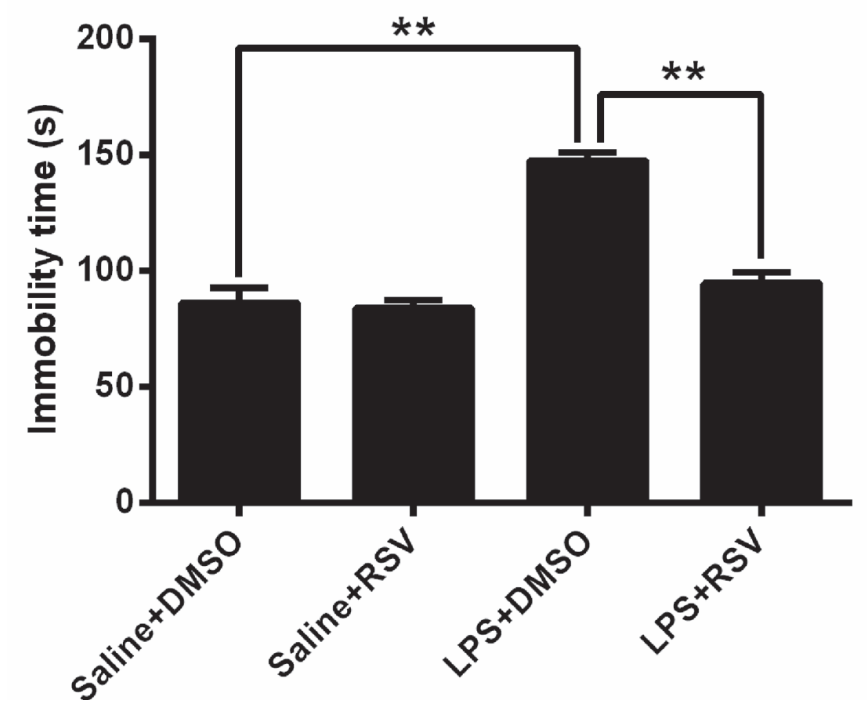

of RGL progenitor cells in the SGZ by stimulating symmetric division. Therefore, our results indicate a novel mechanism for RSV regulation of adult neurogenesis and consequent depressive-like behavior induced by LPS.

\section{RESULTS}

\section{RSV alleviates LPS-induced depression-like behaviors}

The TST and FST tests were widely used to evaluate depression-like behaviors in mice [24, 25], and increased immobility in both the TST and FST is a measure of behavioral despair. As shown in Figure 1A, there were significant differences between the 4 groups for the duration of immobility during the FST $\left(F_{3,28}=38.678\right.$, $p<0.01)$. Post hoc analyses indicated that LPS injected animals (LPS+DMSO) demonstrated significantly more immobility during the FST compared to saline treated control mice (Saline+DMSO) $(p<0.01)$. Pretreatment with RSV (LPS+RSV) significantly reduced the immobility period compared to the LPS treated group ( $p$ $<0.01$ ), however, RSV did not alter immobility durations in the control animals.

In order to confirm the FST results, we analyzed immobility duration using the TST (Figure 1B) and found that LPS injected mice were immobile for a significantly longer duration of time than saline treated control mice $(p<0.01)$. Pretreatment with RSV markedly reduced the

(B)

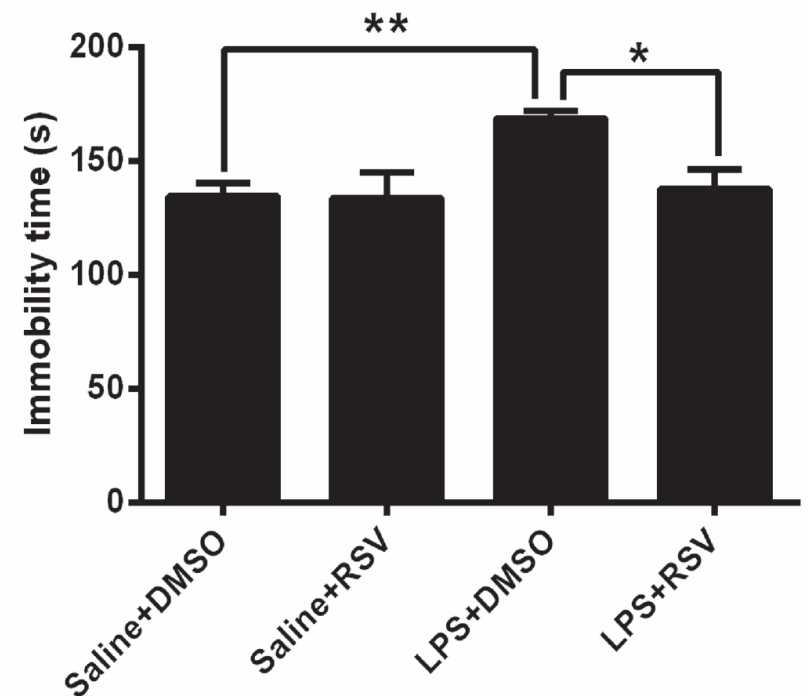

Figure 1: Effects of RSV on the duration of immobility on the forced swimming test (FST) and tail suspension test (TST) in LPS injected mice. A. and B. LPS induced depression-like behaviors on the FST and TST. A. LPS treated mice displayed more immobility time on the FST, and pretreatment with RSV reversed this effect $(n=8)$. B. LPS treated mice displayed an increased duration of immobility on the TST, and pretreatment with RSV reversed this effect $(n=8)$. Data are presented as mean $\pm \mathrm{SEM}$. ${ }^{*} p<0.05$; $* * p<0.01$. 
(A)

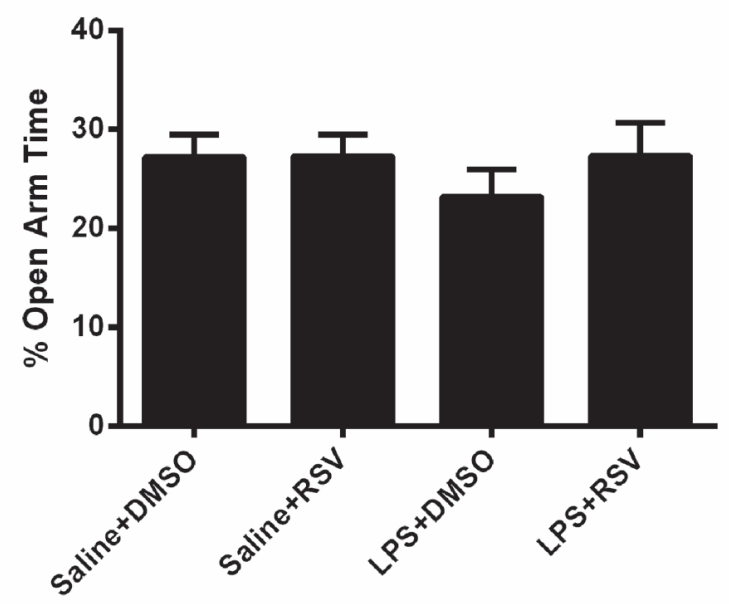

(C)

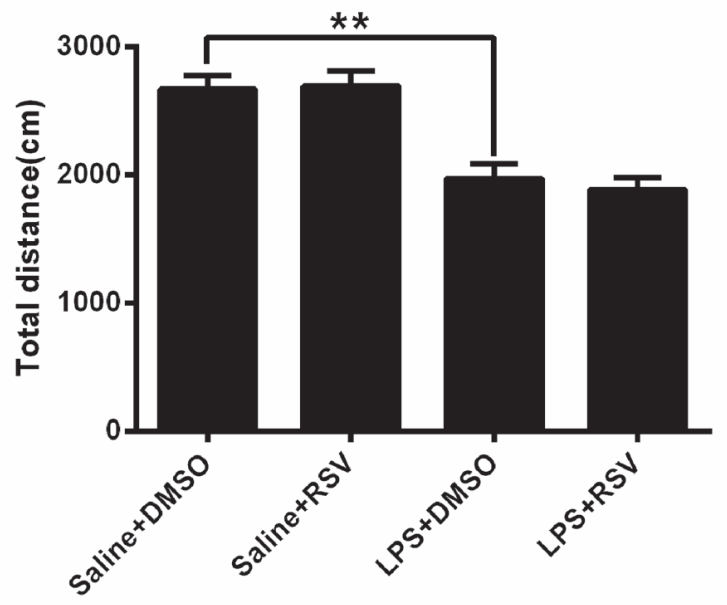

(E)

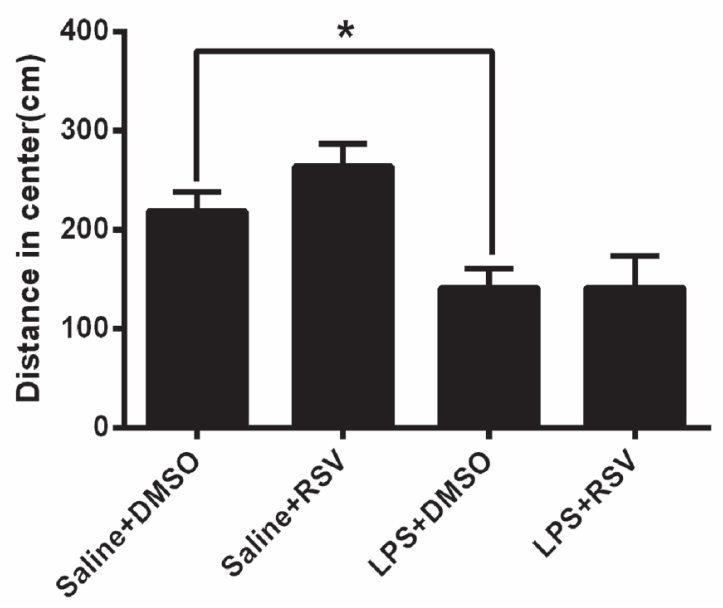

(B)

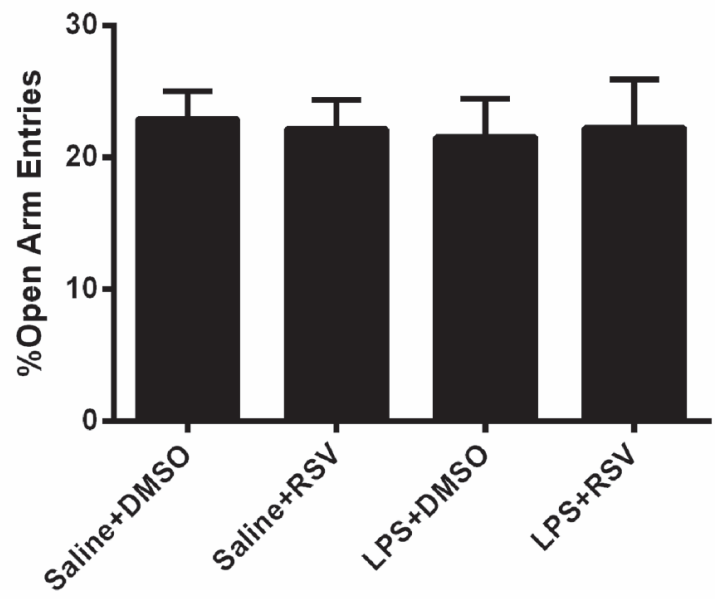

(D)

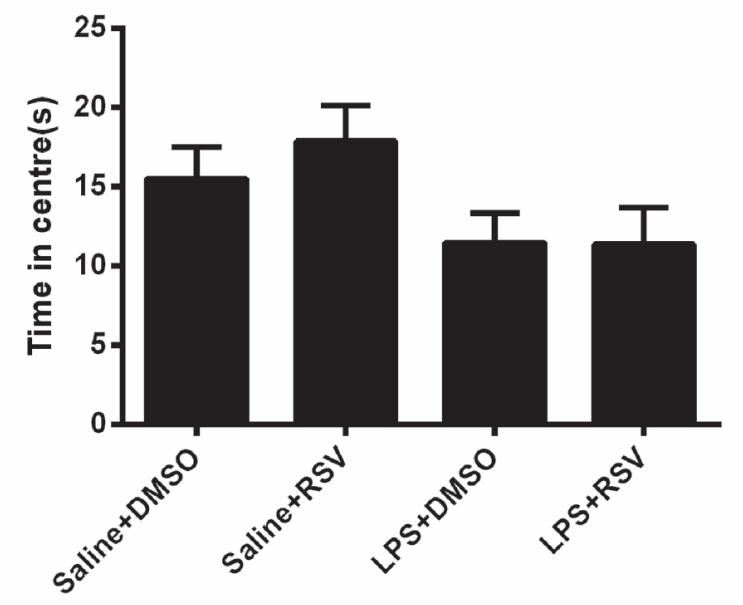

Figure 2: The effect of RSV on LPS injected mice in the elevated plus-maze test and the open field test. A. and $B$. Behavior of the 4 groups of mice in the elevated plus-maze test. There were no difference in the percentage of time spent in the open arms (A) or the percentage of open arm entries (B) between the 4 groups $(n=8)$. C.-E. Behavior of the 4 groups of mice in the open field test. LPS treatment decreased the overall distance traveled $(\mathrm{C})$ and distance in center $(\mathrm{E})$, but there were no significant differences in the duration of time spent in the center of the field (D). Data are presented as mean \pm SEM. ${ }^{*} p<0.05 ; * * p<0.01$. 
duration of immobility on the TST in LPS injected mice $(p<0.05)$.

We next examined a cohort of mice using the elevated plus maze, a common test of anxiety-like behavior in rodents [26]. There were no significant differences in the percentage of time spent in open-arms $\left(F_{3,28}=2.512, p>0.05\right.$; Figure 2A) or percentage of open arm entries $\left(F_{3,28}=.042, p>0.05\right.$; Figure $\left.2 \mathrm{~B}\right)$ between the 4 groups. On the open field test, there were no significant differences between the 4 groups for the duration of time spent in the center of the field $\left(F_{3,28}=2.287, p>0.05\right.$; Figure 2D). However, as shown in Figure 2C, there were significant differences for total distance $\left[F_{3,28}=16.173\right.$, $p<0.01]$. LPS treatment significantly decreased the total distance $(p<0.01$; Figure $2 \mathrm{C}$ ) and distance in center $(p<$ 0.05 ; Figure $2 \mathrm{E}$ ), but pretreatment with RSV did not block these effects $(p>0.05)$.

\section{RSV inhibits LPS-induced over-activation of microglia in the DG-SGZ}

Microglial activation in the SGZ was assessed using ionized calcium binding adapter molecule 1 (Iba1) staining, which demonstrated that the number of Iba-1 immunoreactive cells in the DG-SGZ increased significantly following LPS injection, compared to all other groups $\left(F_{3,16}=14.714, p<0.01\right.$; Figure 3$)$. Iba-1 positive microglia in the hippocampus of saline-treated control animals had smaller cell bodies with fewer and scattered processes (Figure 3A, 3E), but LPS injected mice had enlarged cell bodies with thicker and more condensed processes (Figure 3C, 3G). RSV pretreatment resulted in reduced microglia with activated morphologies following LPS injection (Figure 3D, 3H). RSV alone did not alter Iba-1 positive microglia in the hippocampus of the intact animals (Figure 3B, 3F). Analyses of Iba-1 staining data confirmed that LPS injection increased Iba-1
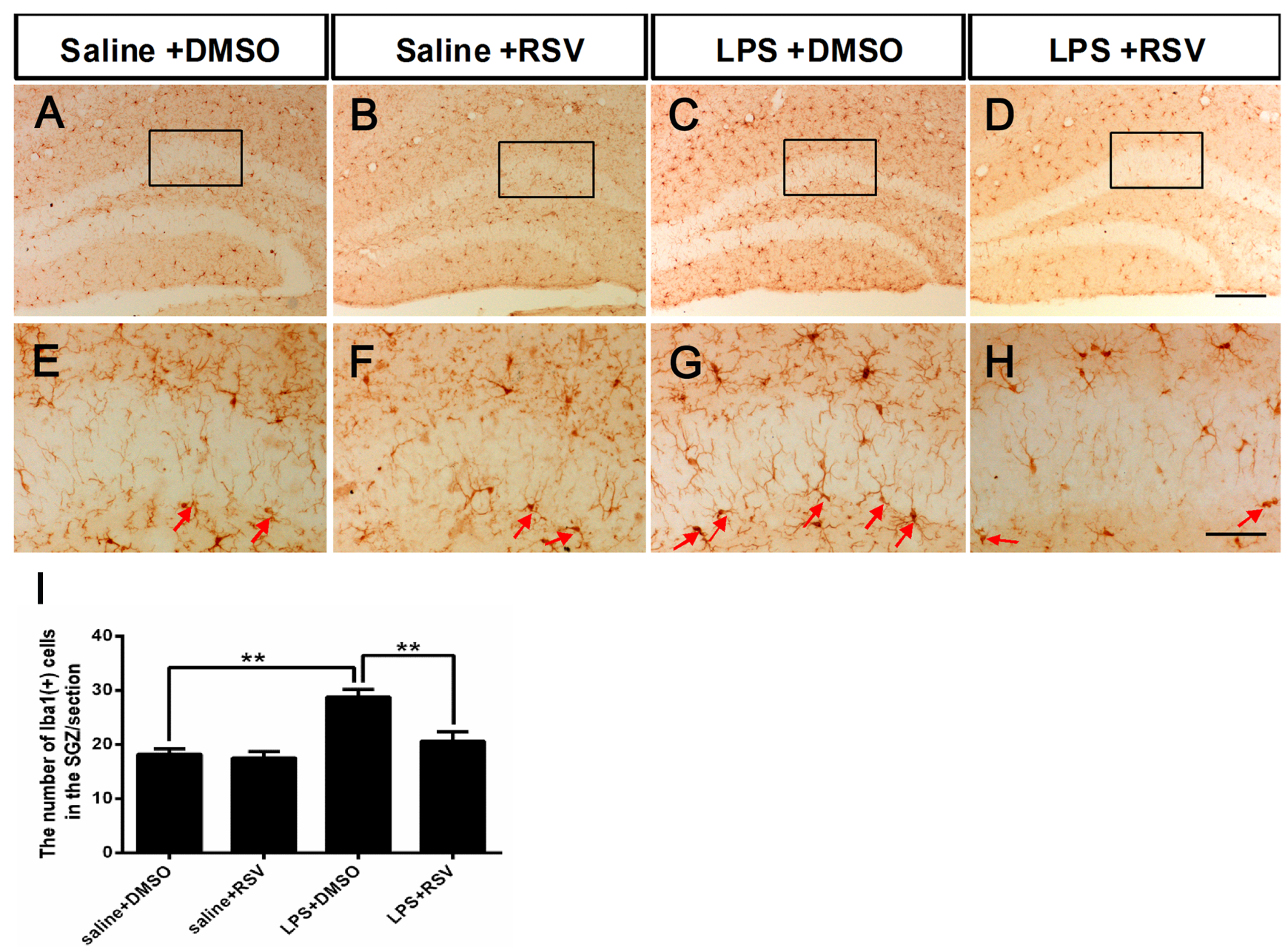

Figure 3: Pretreatment with RSV inhibited LPS-induced over-activation of microglia in the SGZ. A.-D. Microglia in the SGZ of the 4 groups, as shown by immunostaining with the microglia-specific marker Iba1. E.-H. Higher-power views of the boxed areas in (A-D). Arrowheads indicate Iba $1^{+}$cells in the SGZ. I. The number of Iba ${ }^{+}$cells in the SGZ. Data are presented as mean \pm SEM $(n=5)$. $* * p<0.01$. Scale bar in $\mathrm{D}=200 \mu \mathrm{m}$ and applies to (A-D), in $\mathrm{H}=20 \mu \mathrm{m}$ and applies to (E-H). 
immunoreactivity in the SGZ and that RSV pretreatment had an inhibitory effect (Figure 3I).

\section{RSV prevented LPS-induced suppression of hippocampal neurogenesis}

Reduced adult DG neurogenesis contributes to depression-like behaviors [27], while increased hippocampus neurogenesis alleviates depression-like behaviors [28].Therefore, we analyzed the proliferating cell population in the SGZ using the BrdU incorporation assay, which demonstrated that there was a significant treatment effect for the number of $\mathrm{BrdU}^{+}$cells $\left(F_{3,16}=\right.$ 5.29, $p<0.05$; Figure 4A-4D and M). Post hoc analyses indicated that LPS treatment significantly decreased the number of $\mathrm{BrdU}^{+}$cells in the $\mathrm{SGZ}$ compared to the saline treated control group $(p<0.01)$, while RSV increased the number of $\mathrm{BrdU}^{+}$cells in the LPS treated group ( $p<0.01)$, but not in the control group $(p>0.05)$. New granular neurons are produced continuously, and originate in the SGZ of the DG. DCX immunoreactivity
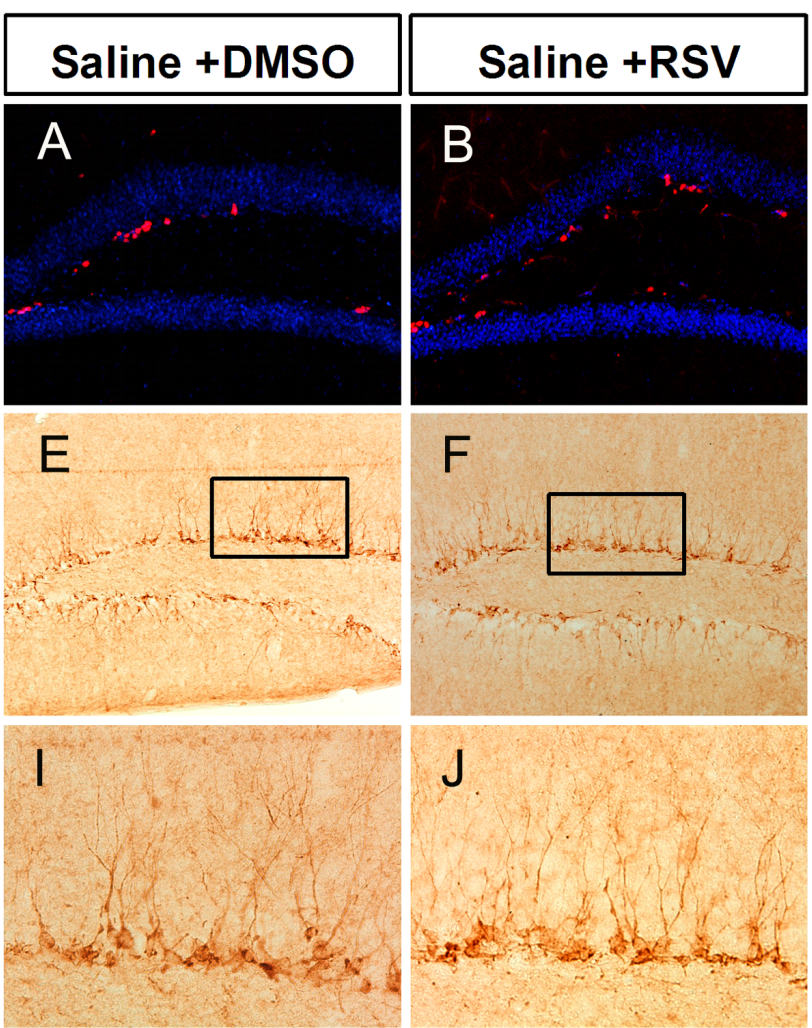

F
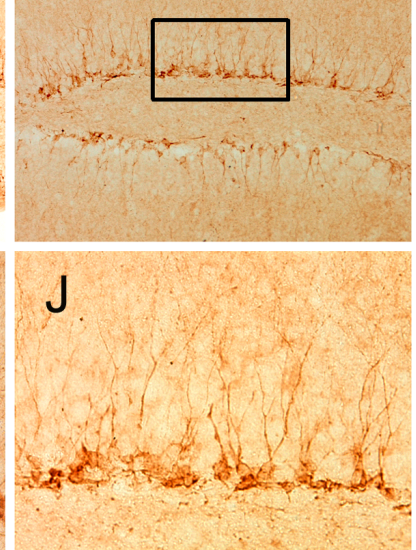

M

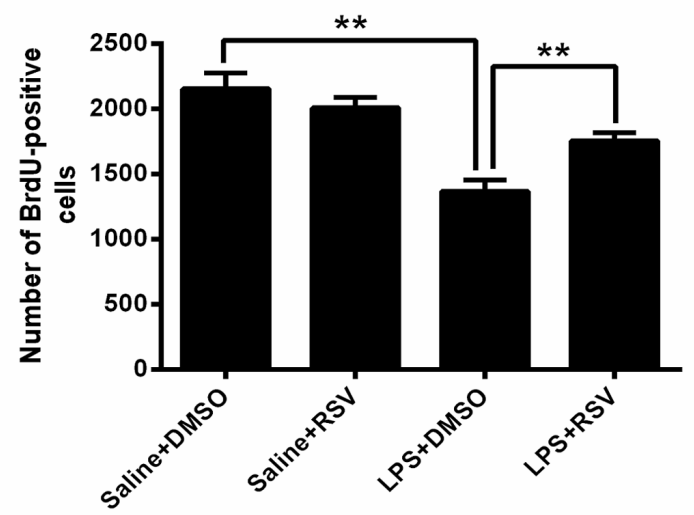

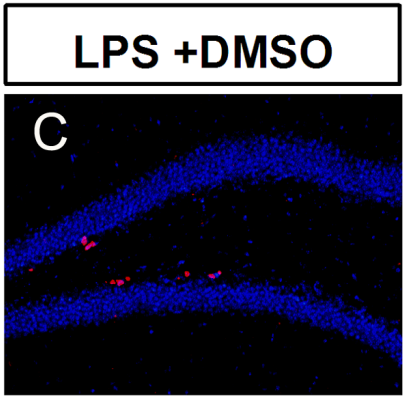
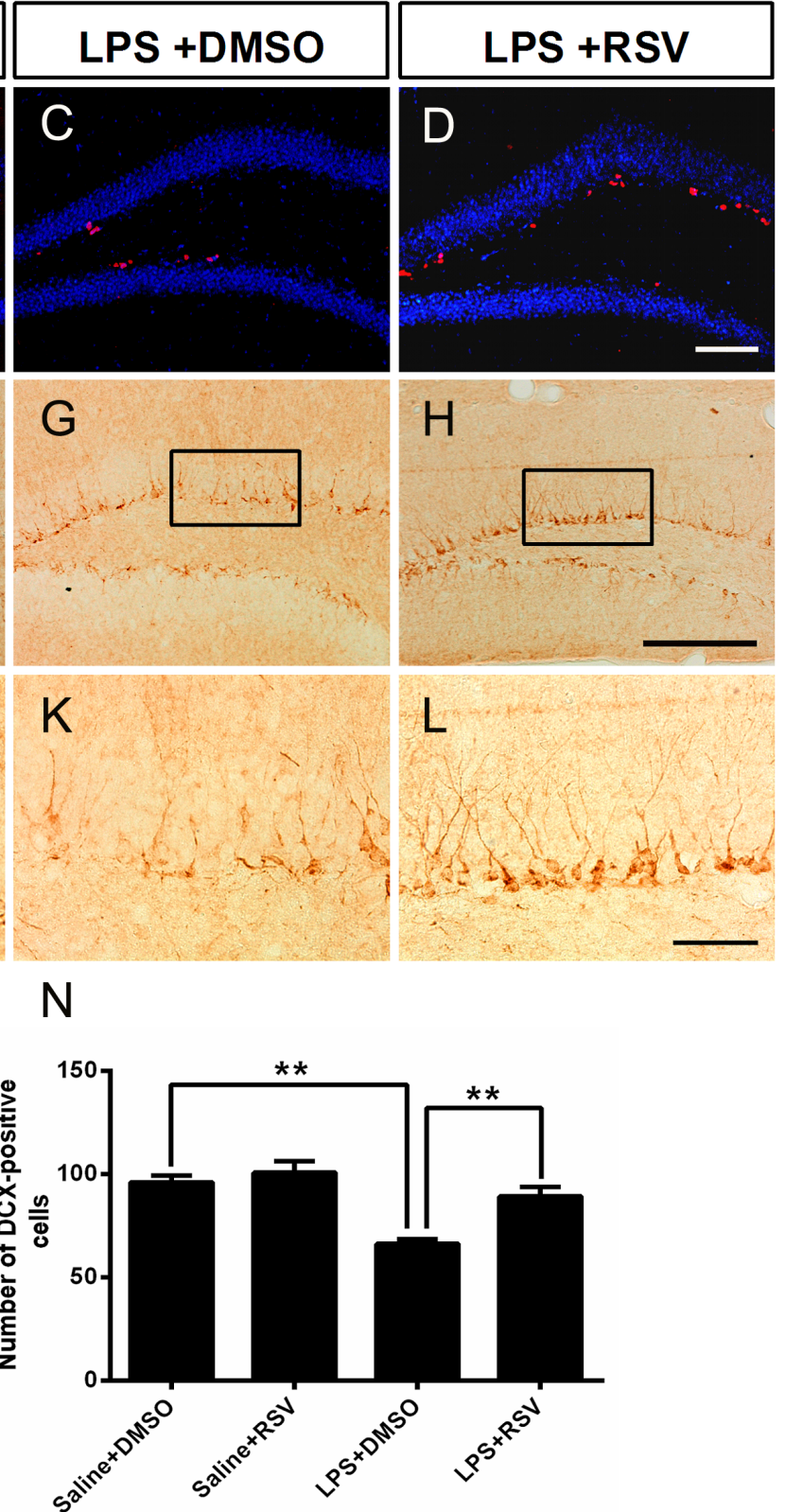

Figure 4: Pretreatment with RSV prevented the LPS-induced decrease of BrdU-positive cells and DCX-positive cells in the SGZ. A.-D. BrdU-positive cells in the SGZ for each of the 4 groups. Mice were sacrificed $24 \mathrm{~h}$ after the last BrdU injection. E.-H. Doublecortin positive $\left(\mathrm{DCX}^{+}\right)$cells in the SGZ. I.-L. Higher-power views of the boxed areas in E-H. RSV treatment reversed the LPSinduced decrease of BrdU-positive cells M. and DCX-positive cells N. Data are presented as mean $\pm \operatorname{SEM}(n=5)$. ${ }^{*} p<0.01$. Scale bar in $(\mathrm{D})=100 \mu \mathrm{m}$ and applies to (A-D), in $(H)=200 \mu \mathrm{m}$ applies to (E-H) and in (L) $=20 \mu \mathrm{m}$ applies to (I-L). 

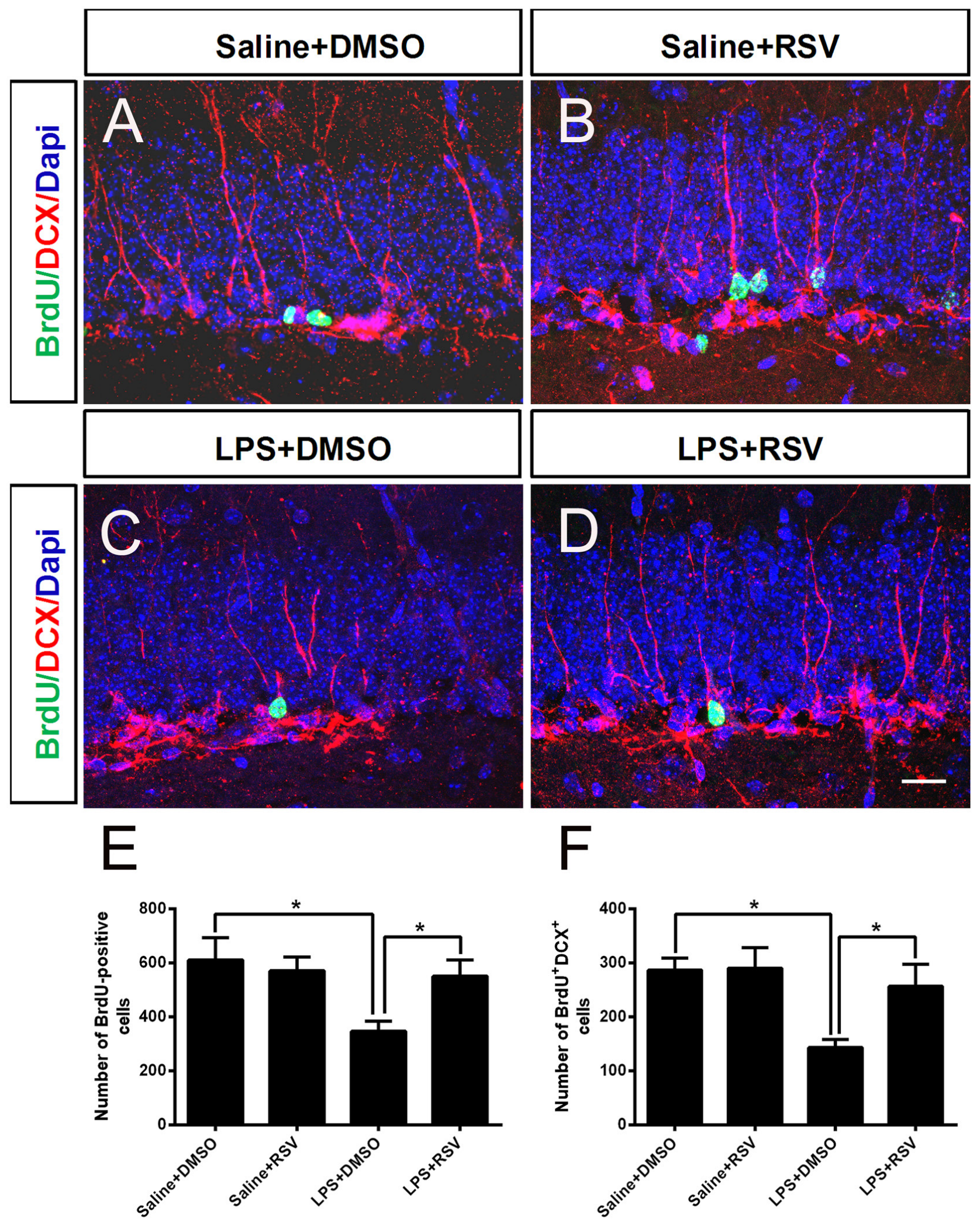

Figure 5: Pretreatment with RSV prevented the decrease of BrdU-positive cells, as well as the number of cells positive for both BrdU and DCX in the DG at $14 \mathrm{~d}$ following BrdU injection. A.-D. BrdU-positive cells and DCX-positive cells in the DG. Mice were sacrificed $14 \mathrm{~d}$ after the last BrdU injection. RSV treatment reversed the decrease of BrdU-positive cells E., as well as BrdU and DCX double-positive cells $\mathbf{F}$. induced $14 \mathrm{~d}$ following LPS injection. Data are presented as mean $\pm \operatorname{SEM}(n=5) .{ }^{*} p<0.05$. Scale bar in (D) $=20 \mu \mathrm{m}$ and applies to (A-D). 
is a method to identify immature neurons, therefore, we assessed DCX positive immature neurons in the SGZ. We found a significant treatment effect for the number of DCX positive immature neurons in the SGZ $\left(F_{3,16}=\right.$ 14.323, $p<0.01$; Figure 4E-4L and 4N), with LPS treated mice possessing significantly fewer DCX positive cells than mice in the saline treated control group $(p<0.01)$. However, pretreatment with RSV reversed this effect ( $p$ $<0.01)$.

We further analyzed the number of $\mathrm{BrdU}^{+}$nuclei, as well as cells positive for both BrdU and DCX, in the DG at $14 \mathrm{~d}$ following BrdU injections (Figure 5). Exposure to LPS significantly decreased the number of BrdU ${ }^{+}$cells $(p$ $<0.05$ ), and this effect was completely blocked by RSV ( $p$ $<0.05$ ) (Figure 5E). Analysis of the $\mathrm{BrdU}^{+} / \mathrm{DCX}^{+}$doublelabeled cells demonstrated that LPS also decreases the number of immature neurons $(p<0.05)$, and this effect was blocked by RSV $(p<0.05)$ (Figure 5F). These data indicate that RSV treatment prevented LPS-induced impairment of hippocampal neurogenesis.

\section{RSV alleviates LPS-mediated exhaustion of NPCs in the DG-SGZ}

In the adult hippocampus, a reduction in cellular proliferation in the SGZ of the DG may result from a decline in available NSCs. NSCs primarily include 2 types of NSCs: SOX2 and GFAP double-positive $\left(\mathrm{SOX}^{+} / \mathrm{GFAP}^{+}\right)$cells (type 1$)$, and SOX2-positive and GFAP-negative $\left(\mathrm{SOX}^{+} / \mathrm{GFAP}^{-}\right.$) cells (type 2$)[10,11]$. In order to explore the treatment effects on NPCs, we used SOX2 and GFAP double-labeling, with two-way ANOVA demonstrating significant differences between the 4 groups
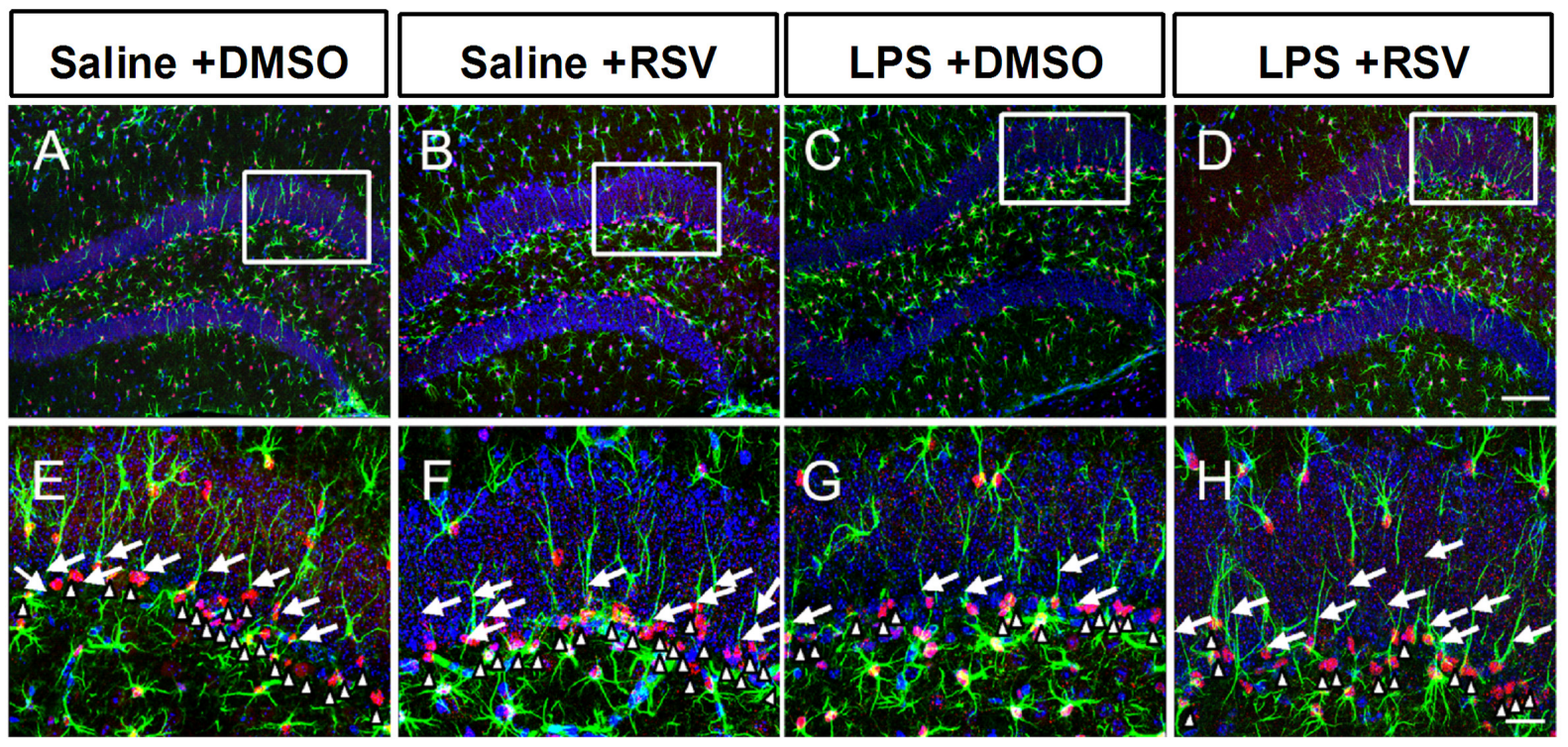

|
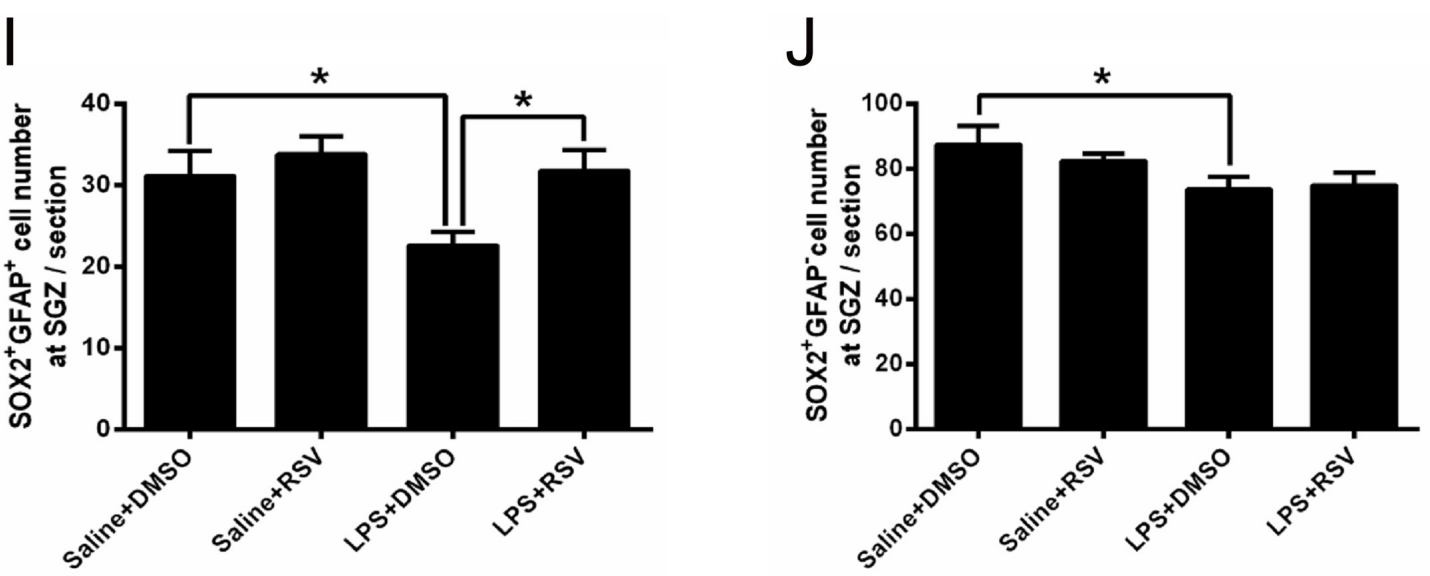

Figure 6: Pretreatment with RSV inhibited the LPS-induced decrease in neuronal stem cells in the SGZ. A.-D. SOX2 and GFAP double immunostaining in the DG-SGZ for each of the 4 groups. E.-H. Higher-power views of the boxed areas in (A-D). Arrowheads indicate $\mathrm{SOX}_{2}{ }^{+} \mathrm{GFAP}^{+}$cells in the SGZ. White triangle decorators indicate SOX2 $2^{+}$GFAP- cells in the SGZ. LPS treatment decreased the number of SOX2-positive and GFAP-positive (SOX2 ${ }^{+} \mathrm{GFAP}^{+}$) cells I., as well as SOX2-positive and GFAP-negative (SOX2 $2^{+} \mathrm{GFAP}^{-}$) cells J. in the SGZ, but pretreatment with RSV only inhibited the LPS-induced (SOX2 ${ }^{+} \mathrm{GFAP}^{+}$) cell decrease. Data are presented as mean $\pm \mathrm{SEM}$ $(n=5) . * p<0.05$. Scale bar in $\mathrm{D}=100 \mu \mathrm{m}$ and applies to (A-D), in $\mathrm{H}=25 \mu \mathrm{m}$ and applies to (E-H). 
$\left(F_{3,16}=4.203, p<0.05\right.$; Figure 6I). Post-hoc analyses indicated that LPS treatment significantly decreased the number of $\left(\mathrm{SOX}^{+} / \mathrm{GFAP}^{+}\right)$cells in the SGZ compared to the saline treated control group $(p<0.05)$, whereas RSV increased the number of SOX $2^{+} / \mathrm{GFAP}^{+}$cells in LPS treated group ( $p<0.05)$, but not in the control group $(p>0.05)$. There were no significant differences between groups for $\mathrm{SOX}^{+} / \mathrm{GFAP}^{-}$cells in the $\mathrm{SGZ}\left(F_{3,16}=2.421, p=0.104\right.$; Figure $6 \mathrm{~J})$. Specifically, LPS treatment decreased $\mathrm{SOX} 2^{+}$ GFAP $^{-}$cells in the SGZ $(p<0.05)$, but this effect was not reversed by RSV pretreatment $(p>0.05)$. RSV primarily reversed LPS-induced reductions of type $1 \mathrm{NSCs}$ in the $\mathrm{DG}$, indicating that maintenance of the NSC population impacts RGLs.

\section{RSV modulates LPS-induced imbalances between symmetric and asymmetric division patterns of RGL progenitor cells in the DG-SGZ}

Type 1 RGLs in the DG can self-renew in adults by either asymmetric or symmetric cell division, therefore, NSCs are maintained throughout adulthood [11]. The modes of cell division of RGLs are essential to hippocampal neurogenesis. Two examples of these modes are asymmetric cell division, which results in a single daughter neuron and a mother cell that remains a progenitor cell, and symmetric cell division, which increases the number of progenitor cells [29, 30]. In order to investigate the effects of RSV and LPS on the mode of cell division, we examined alignment of the newly generated pairs of RGL progenitor cells in the granule cell layer (GCL) $1 \mathrm{~d}$ after BrdU injections. We found that the LPS treatment group had a significantly lower percentage of symmetric division compared to the control group (Saline+DMSO, 77.5\%; LPS+DMSO, 39.5\%; $p<$ 0.01 ; Figure 7E). Furthermore, pretreatment with RSV alleviated the effects induced by LPS (LPS+DMSO, $39.5 \%$; LPS+RSV, 76\%. $P<0.01$; Figure 7E), which indicates that RSV may alter the RGL progenitor cells division mode, thereby influencing the available progenitor cells.

\section{RSV reverses LPS-induced increases in NF- $\mathrm{KB}$ and decreases Hes1 and Sirt1 protein expression in the hippocampus}

The Sirt1/NF- $\kappa \mathrm{B}$ signaling pathway is involved in LPS-induced inflammation [31], therefore, we performed western blotting to investigate whether RSV treatment inhibits LPS-induced inflammation via this signaling

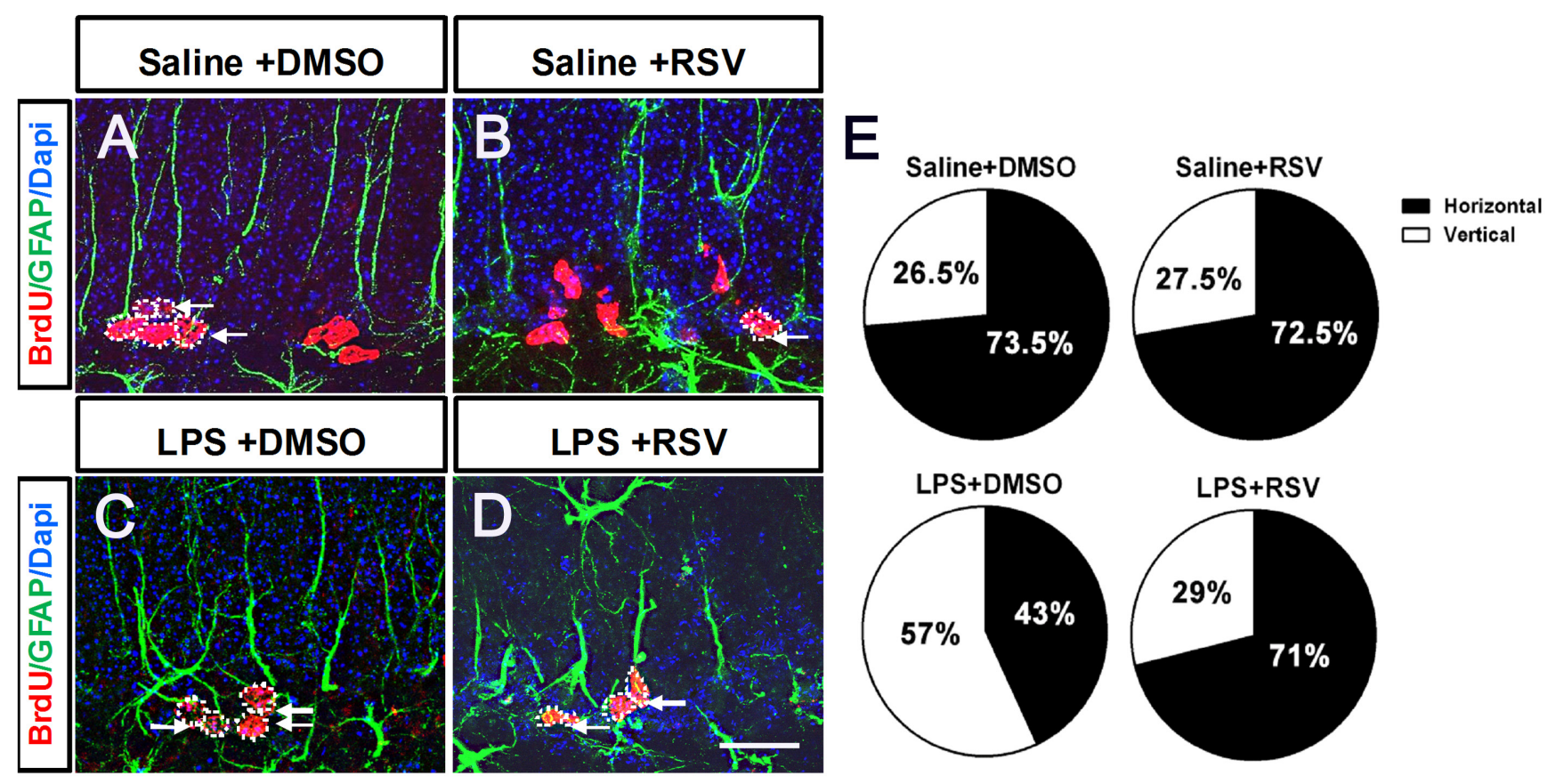

Figure 7: Pretreatment with RSV modulated the division mode of RGL progenitor cells in the GCL that was altered by LPS. A.-D. BrdU and GFAP double immunostaining in the GCL for each of the 4 groups. There were differently aligned patterns of BrdU-labeled RGL progenitor cells, including horizontally and vertically aligned patterns. Single arrowhead indicates horizontally aligned patterns. Two arrowheads arranged along the up-down direction indicate vertically aligned patterns. E. Quantitative analysis of the cell alignment modes between the 4 groups. LPS treatment decreased the horizontally aligned pattern compared to the other groups (Saline+DMSO, 77.5\%; LPS+DMSO, 39.5\%. $p<0.01$ ), and pretreatment with RSV reversed this effect (LPS+DMSO, 39.5\%; LPS+RSV, $76 \% . p<0.01)$. Data are presented as mean $\pm \operatorname{SEM}(n=5)$. Scale bar in $\mathrm{D}=20 \mu \mathrm{m}$ and applies to (A-D). 
pathway. Hippocampal protein expression of $\mathrm{NF}-\kappa \mathrm{B}$ was significantly different between the 4 groups $\left(F_{3,8}=\right.$ $6.868, p<0.05$; Figure $8 \mathrm{~A}, 8 \mathrm{D})$, and post-hoc analyses demonstrated that NF- $\mathrm{B}$ protein expression was upregulated in the LPS treatment group compared to the saline treated control group $(p<0.01)$. Furthermore, pretreatment with RSV repressed NF- $\kappa \mathrm{B}$ protein expression in the hippocampus $(p<0.01)$. Therefore, there were marked between-group differences for Sirt1 protein expression in the hippocampus $\left(F_{3,8}=4.462, p<0.05\right.$; Figure $8 \mathrm{~B}, 8 \mathrm{E})$. Compared to saline treated control mice, Sirt1 protein expression was significantly decreased $(p<$ 0.05 ), but pretreatment with RSV reversed this effect ( $p$ $<0.05)$.

The Hairy and Enhancer of Split homologue-1 (Hes1) is essential to the maintenance of RGLs [32], so we also assessed Hes1 protein expression in the mice hippocampus, with findings demonstrating differences between the 4 groups $\left(F_{3,8}=13.094, p<0.01\right.$; Figure 8C, $8 \mathrm{~F})$. Specifically, LPS treatment significantly decreased Hes1 protein expression compared to the saline treated control group ( $p<0.01$ ), but pretreatment with RSV reversed the effect $(p<0.01)$. In conjunction, the results indicate that RSV reverses LPS-induced inhibition of Hes1 expression. Furthermore, this effect may occur via

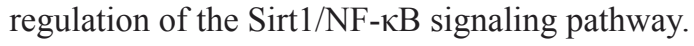

\section{DISCUSSION}

In the present study, we found that LPS treatment increased depressive-like behaviors, as assessed by the TST and FST, without affecting anxiety-like behaviors. The findings also corroborate previous reports demonstrating that RSV ameliorates depression-like behaviors in mice, which were induced by repeated corticosterone [19] and LPS [21]. The anti-depressant activities of RSV in the present experiments do not appear to be the result of an overall attenuation of psychomotor activity, as locomotor activity was unaffected by RSV treatment.

It should be noted that behavioral changes did not occur in naïve mice, rather, RSV attenuated behavioral changes induced by i.p. LPS. We observed RSV pretreatment also decreased Iba-1 labeling of microglia in the SGZ elicited by LPS, which may be partially responsible for the observed anti-depressant activity. We also demonstrated a decrease in the number of proliferating SGZ cells following LPS administration. Previous research has indicated that LPS-induced neuroinflammation reduces neurogenesis in the hippocampus [33, 34]. Gebara et al. found an inverse correlation between the number of microglia present in the hippocampus and NSC proliferation [35]. Consistent with these findings, we have previously demonstrated that memantine promotes hippocampal neurogenesis in APP/ PS1 mice, partially by inhibiting microglial over-activation [36]. It has been reported that RSV protected neurons by suppressing microglial activation [37]. Unexpectedly, RSV effectively reversed suppression of hippocampal neurogenesis following LPS. Similarly, Kodali et al have confirmed that RSV-treated animals displayed increased net neurogenesis and diminished microglial activation in the hippocampus [38]. Meanwhile, we also noticed that RSV had no effect in animals not exposed to LPS. There

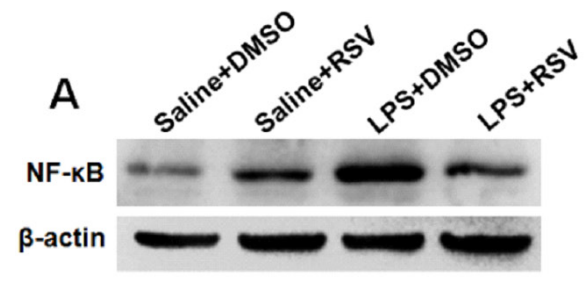

D

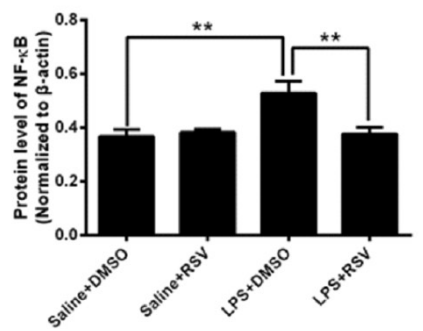

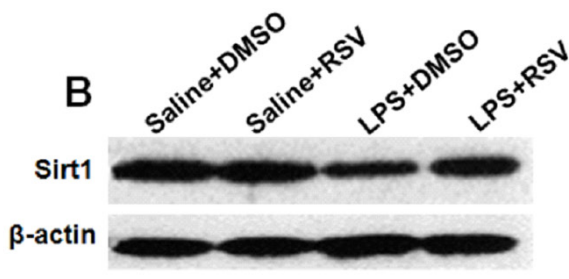

E

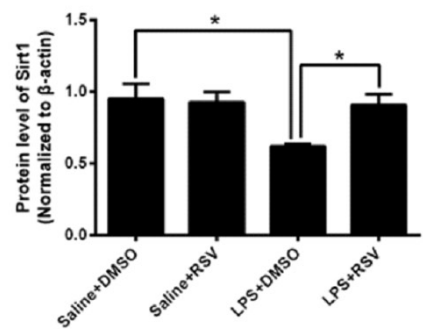

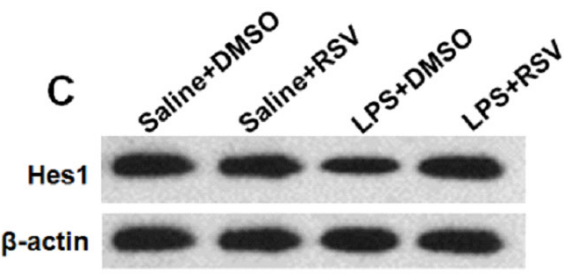

$F$

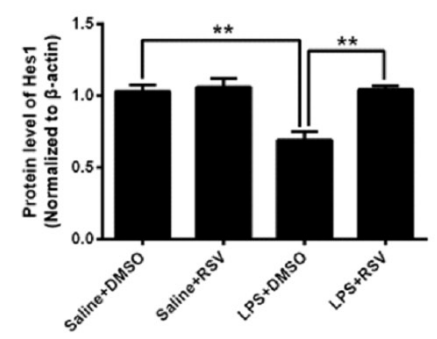

Figure 8: Expression of NF-кB, Sirt1, and Hes1 in the mouse hippocampus. A. and B. Western blots assessing NF- $\mathrm{BB}$ and Sirt1 expression in the hippocampus of the 4 groups. LPS treatment significantly increased NF- $\mathrm{B}$ expression in the hippocampus, whereas pretreatment with RSV inhibited this effect D. Conversely, compared to the saline treated group, LPS treatment decreased Sirt1 expression in the hippocampus, whereas pretreatment with RSV reversed this effect E. C. Western blots assessing Hes 1 expression in the hippocampus of the 4 groups. Hes1 was significantly decreased in the hippocampus of LPS treated mice, whereas pretreatment with RSV prevented this effect $\mathbf{F}$. Data are presented as mean $\pm \operatorname{SEM}(n=3) *{ }^{*} p<0.05 ; * *<0.01$. 
are discrepancies in the effect of RSV on DG neurogenesis of intact mice. Torres-Pérez et al has found 6 months of age female Balb/C mice received two weeks of $\mathrm{RSV}$ (40 mg/kg) increased DG neurogenesis [39]. However, another study from Park et al have demonstrated that male C57BL/6 mice (4 weeks old) received two weeks of RSV (1-10 mg/kg) inhibited DG neurogenesis [40]. Probably, the different dosage of RSV and mice of age, sex and genetic background could produce different effects on intact animals.

The available NSCs determine the capacity of adult hippocampal neurogenesis, and we found that LPS treatment decreased both types of NSCs in the SGZ, but that pretreatment with RSV only reversed the effect in type 1 cells. Whether type 1 cells convert to type 2 cells is not fully understood $[10,11]$, it is very likely that RSV rescued the deficits of the self-renewal capacity of type 1 cells induced by LPS which may contribute to the recovered neurogenesis in LPS-injected mice.

RGLs in the SGZ experience 2 types of division patterns: asymmetrical and symmetrical patterns. Asymmetrical division patterns produce differentiation of RGLs into astrocytes or neurons, thus exhausting the available stem cells in the DG-SGZ of the hippocampus, whereas symmetrical division increases the number of RGL progenitor cells and enhances neurogenesis [29, 30]. In the present study, RSV increased the population of RGL progenitor cells by promoting symmetrical division. These findings indicate that RSV reversed the LPS-induced decrease in hippocampal neurogenesis by initiating continuous neurogenesis via symmetrical division. Other contributors to enhanced neurogenesis such as antidepressants, running, and enriched environments may not increase the number of the primary progenitor cells [41-43].

Although changes to division modes of RGLs have been observed under various conditions, the molecular mechanisms controlling the balance of symmetric and asymmetric division had not been fully elucidated. The Notch1/Hes1 signaling pathway has been implicated in regulation of RGL division patterns [44, 45]. The absence of the Hes 1 gene leads to decreased NPCs in the DG, a reduction in cell number, and a lack of later-born neurons [32]. Previous research has confirmed that activation of Sirt1 by RSV is involved in self-renewal, multipotency, and fate determination of NPCs [46, 47]. We previously demonstrated that RSV pretreatment reversed inhibition of Hes 1 expression in the hippocampus induced by alcohol exposure through up-regulation of Sirt1 [17]. We also demonstrated that RSV pretreatment reversed an LPSinduced reduction of Sirt1 and Hes1 in the hippocampus, which may be involved in modulation of the division patterns of RGLs.

In contrast, we also found that RSV alone has no effect on RGL division mode or Hes1 expression. Inhibition of NF- $\kappa \mathrm{B}$ signaling by Sirt1 deacetylase and its agonist, RSV, is strongly neuroprotective [48, 49]. Additionally, we observed that RSV pretreatment also inhibited the LPS-induced increase in NF- $\kappa \mathrm{B}$ in the hippocampus. A previous study demonstrated that acute and chronic stress-induced activation of NF- $\kappa \mathrm{B}$ signaling contributes to decreased proliferation of RGL progenitor cells [50]. We hypothesized that RSV-induced activation of Sirt1 contributes to the effects of NF- $\kappa \mathrm{B}$ in reversing LPS-induced decreases in hippocampal neurogenesis. Recent evidence demonstrated an association between the Sirt1 gene and major depressive disorder [51]. Aberrant expression and/or function of Sirt1 may contribute to the pathophysiology of depression via neuroinflammation and dysregulation of neurogenesis. Further research is needed, in order to clarify the mechanisms of Sirt1 mediated RGL protection and modulation of division patterns.

In conclusion, our data provide the first evidence that RSV-induced activation of Sirt1 reverses LPS-induced depression-like behaviors by enhancing neurogenesis. RSV activation of Sirt1 has unique roles in promoting proliferation and increasing the available RGL progenitor cells in the GCL by stimulating symmetric division. Our findings also provide a new model for understanding the promising role of RSV in treating depression by promoting neurogenesis.

\section{MATERIALS AND METHODS}

\section{Animals}

Adult male C57/BL6 mice were provided by the Third Military Medical University and were housed grouped in a temperature-controlled room with a standard 12-h light/12-h dark cycle and ad libitum access to food and water. Eight-week-old mice were used at the start of the experiments. All experimental procedures were approved by Third Military Medical University and were performed according to the guidelines of laboratory animal care and use. All efforts were made to reduce the number of animals used and to minimize their discomfort.

\section{Drug treatment}

RSV (Sigma-Aldrich, R5010, St. Louis, MO, USA) was dissolved in DMSO (Sigma-Aldrich) and ethanol $50 \% \mathrm{~V} / \mathrm{V}$ and diluted in saline at a concentration of 20 $\mathrm{mg} / \mathrm{mL}$ [52]. LPS from Escherichia coli 026:B6 (SigmaAldrich) was dissolved in $0.9 \% \mathrm{NaCl}$ at a concentration of $1 \mathrm{mg} / \mathrm{mL}$. Mice were randomly divided into the following 4 groups: (1) pretreatment with DMSO, followed by normal saline $(0.9 \% \mathrm{NaCl})$ (Saline+DMSO), (2) pretreatment with RSV, followed by normal saline (0.9 $\% \mathrm{NaCl}$ ) (Saline+RSV), (3) pretreatment with DMSO, followed by LPS (LPS+DMSO), or (4) pretreatment 
with RSV followed by LPS (LPS+RSV). RSV was administered by intraperitoneal (i.p.) injections $(20 \mathrm{mg} /$ $\mathrm{kg}$ ) for 14 consecutive days, as previously described [52]. The control groups received an equivalent injection of DMSO. After 14 consecutive days of RSV or DMSO administration, mice also received i.p. injections of saline or LPS ( $1 \mathrm{mg} / \mathrm{kg}$ ) for 5 consecutive days. The dose of LPS was based on a previous study [53].

Bromodeoxyuridine (BrdU; Sigma-Aldrich) was dissolved in $0.9 \% \mathrm{NaCl}$ [17]. In order to assess cell proliferation in the DG, mice received BrdU every 2 hours, for a total of 3 injections at a dose of $100 \mathrm{mg} / \mathrm{kg}$, and were then sacrificed $24 \mathrm{~h}$ after the first BrdU injection. In order to analyze neurogenesis in the DG, mice were sacrificed 2 weeks after the first BrdU injection, and $\mathrm{BrdU}^{+}$cells as well as BrdU ${ }^{+}$cells colabeled with doublecortin (DCX ) were quantified.

\section{Behavioral experiments}

All the behavioural tests began $12 \mathrm{~h}$ after the last LPS injection. Mice were acclimatized to the experimental room for at least $30 \mathrm{~min}$ prior to each test. Besides, the less stressful test (open field test) was conducted prior to the more stressful tests (elevated plus maze, forced swim test, tail suspension test).

\section{Forced swimming test (FST)}

Twelve hours after the last LPS or saline administration, mice completed the forced swimming test (FST) according to previous methods, with minor modification [54]. Briefly, each mouse was placed individually in a cylinder (height: $20 \mathrm{~cm}$, diameter: $10 \mathrm{~cm}$ ) for $6 \mathrm{~min}$, which was filled with $10 \mathrm{~cm}$ height of water that was $25^{\circ} \mathrm{C}$ in order to avoid a temperature-related stress response. Immobility durations were determined by recording the time that the mice remained floating in the water in an upright position and stopped struggling, typically moving slowly to keep their heads above water. The immobility durations were recorded and analyzed during the last $4 \mathrm{~min}$ of the $6 \mathrm{~min}$ test. Increased duration of immobility indicated a state of helplessness.

\section{Tail suspension test (TST)}

The tail suspension test was performed according to previous methods, with minor modification [55]. In brief, mice were suspended by a hook that was both acoustically and visually isolated, and which was $50 \mathrm{~cm}$ above the floor. The hook was placed approximately $1 \mathrm{~cm}$ from the tip of the tail. Mice were suspended for $6 \mathrm{~min}$, and the immobility duration was recorded and analyzed during the last $4 \mathrm{~min}$ of the $6 \mathrm{~min}$ test.

\section{Open-field test (OFT)}

The open-field test was performed according to previous methods [56], using an open-field activity system
(Biowill, Shanghai, China) and activity software (Biowill). Mice were placed in the center of the open-field box and activity was recorded for a period of $5 \mathrm{~min}$. The total and center-area distances were measured and the duration of time in the central area was recorded. After each test, a solution of $10 \%$ alcohol was used to clean the square arena.

\section{Elevated plus maze}

The elevated plus maze was used to assess anxietylike behavior. According to a previous protocol [57], the mouse was initially placed in the center area facing an open arm. The duration of time for the mouse to enter any of the 4 arms was recorded when all 4 paws crossed from the central region into an arm. The duration of time spent in the open arms and the number of total arm entries during the 5 min testing period were recorded.

\section{Immunohistochemistry and immuno-fluorescence}

According to our previous methods [36], mice were deeply anesthetized with an overdose of isoflurane and transcardially perfused with $0.01 \mathrm{M}$ phosphatebuffered saline (PBS, $\mathrm{pH} 7.4$ ) for 5-10 min, followed by $4 \%$ paraformaldehyde in $0.1 \mathrm{M}$ phosphate buffer (PBS, $\mathrm{pH}$ 7.4) for 15-20 min. Whole brains were removed and post-fixed in the same fixative for $3-4 \mathrm{~d}$ at $4{ }^{\circ} \mathrm{C}$ followed by $30 \%$ sucrose treatment at $4{ }^{\circ} \mathrm{C}$. Serial coronal brain sections ( $25 \mu \mathrm{m}$ in thickness) were cut on a cryostat and stored at $-20{ }^{\circ} \mathrm{C}$ in cryoprotectant solution $(30 \%$ ethylene glycol, $30 \%$ sucrose in $0.01 \mathrm{M}$ PBS). The sections were first washed in $0.01 \mathrm{M}$ PBS to remove the cryoprotectant solution, and then incubated in $3 \% \mathrm{H}_{2} \mathrm{O}_{2}$ for $30 \mathrm{~min}$ at room temperature to quench endogenous peroxidase, followed by washing with $0.01 \mathrm{M}$ PBS. The sections were then incubated with primary antibodies including rabbit anti-Iba1 (1:1000, Wako, CA, USA) or goat antiDCX (1:200, Santa Cruz Biotechnology, CA, USA), in $1 \%$ bovine serum albumin (BSA) and $0.1 \%$ Triton $\mathrm{X}-100$ $\left(12 \mathrm{~h}, 4^{\circ} \mathrm{C}\right)$. BSA $(1 \%)$ replaced the primary antibodies in the negative controls. After washing, the sections were incubated with biotinylated secondary antibody (1:200, Dako, Glostrup, Denmark) (2 h, $\left.37^{\circ} \mathrm{C}\right)$, followed by the avidin- biotin complex (Dako). Finally, staining was visualized and photographed under a Zeiss Axiovert microscope (Oberkochen, Germany) equipped with a Zeiss AxioCam digital color camera connected to the Zeiss AxioVision 3.0 system.

For BrdU and GFAP or BrdU and DCX double staining, the sections were treated with $2 \mathrm{~N} \mathrm{HCl}$ at $37^{\circ} \mathrm{C}$ for $30 \mathrm{~min}$ to denature the DNA, followed by washing with $0.01 \mathrm{M}$ PBS 3 times for $10 \mathrm{~min}$ before being incubated with mouse anti-BrdU (1:200, BD Biosciences, San Jose, CA, USA) and rabbit anti-GFAP (1:200, Zhongshan, Beijing, China) or with mouse anti-BrdU (1:200, BD Biosciences) and goat anti-DCX (1:200, Santa Cruz 
Biotechnology) in $1 \%$ BSA and $0.1 \%$ Triton X-100 for $12 \mathrm{~h}$ at $4{ }^{\circ} \mathrm{C}$. After washing, sections were incubated with fluorescence-tagged secondary antibodies including $\mathrm{Cy} 3$ (1:500, donkey anti-mouse, Jackson ImmunoResearch, West Grove, PA, USA) and Alexa 488 (1:500, donkey antirabbit, Jackson ImmunoResearch) or Cy3 (1:500, donkey anti-goat, Jackson ImmunoResearch) and Alexa 488 (1:500, donkey anti-mouse, Jackson ImmunoResearch) for $2 \mathrm{~h}$ at $37^{\circ} \mathrm{C}$. Nuclei were subsequently stained with 4',6-diamidino-2-phenylindole (DAPI, Beyotime, China). For SOX2 and GFAP double staining, sections were washed 3 times with $0.01 \mathrm{M}$ PBS for $10 \mathrm{~min}$ before being incubated with rabbit anti-SOX2 (1:1000, Abcam, UK) and mouse anti-GFAP (1:500, Millipore, Temecula, CA, USA) in $1 \%$ BSA and $0.1 \%$ Triton $\mathrm{X}-100$ for $12 \mathrm{~h}$ at 4 ${ }^{\circ} \mathrm{C}$. Sections were then incubated with the fluorescencetagged secondary antibodies Alexa 488 (1:500, donkey anti-mouse, Life Technologies, USA) and Cy3 (1:500, donkey anti-rabbit, Jackson ImmunoResearch) for $2 \mathrm{~h}$ at $37^{\circ} \mathrm{C}$ ). Nuclei were subsequently stained with DAPI. Sections were visualized using a confocal laser-scanning microscope (Leica TCS-SP2, laser lines at 488, 543, 633, Heidelberg, Germany) and analyzed with Leica imaging software.

\section{Western blotting}

Hippocampus samples were isolated and homogenized in ice-cold RIPA lysis buffer (Beyotime, Shanghai, China). After centrifugation of lysates $(15,000$ $g$, for $5 \mathrm{~min}$ at $4{ }^{\circ} \mathrm{C}$ ), the protein concentration was determined using a bicinchoninic acid kit (Beyotime Institute of Biotechnology, Shanghai, China). Protein samples (30 $\mu \mathrm{g}$ per lane) were separated on a $12 \%$ SDS-polyacrylamide gel at $80 \mathrm{~V}$ for $120 \mathrm{~min}$, and then transferred onto polyvinylidene fluoride (PVDF) membranes at $250 \mathrm{~mA}$ for $60 \mathrm{~min}$. The membranes were blocked with Tris-buffered saline (TBS) containing $0.1 \%$ Tween 20 (TBST) and 5\% fat-free milk for $3 \mathrm{~h}$ at room temperature. The membranes were then incubated (overnight at $4{ }^{\circ} \mathrm{C}$ ) with rabbit antibodies against Hes 1 (1:1000, Chemicon, CA, USA), Sirt1 (1:1000, Chemicon), and NF- $\mathrm{B}$ (1:2000, BD Biosciences), as well as a mouse antibody against $\beta$-actin (1:2000, Cell CWBIO, Beijing, China). Membranes were then incubated for $1 \mathrm{~h}$ at room temperature with a peroxidase-conjugated goat antirabbit immunoglobulin G (IgG; 1:2000, Santa Cruz Biotechnology) or goat anti-mouse immunoglobulin G (IgG; 1:2000, Santa Cruz Biotechnology). All western blotting data are representative of at least 3 independent experiments. Specific protein bands on the membranes were visualized by the enhanced chemiluminescence (ECL) method (Amersham, Piscataway, NJ, USA), according to the manufacturer's instructions. The relative intensities of Hes1, Sirt1, and NF- $\mathrm{KB}$ were normalized to the internal reference protein $\beta$-actin. Three animals per group were used for analysis.

\section{Cell counting and unbiased stereology}

According to our previous methods [36], an average of five sections per mouse was analyzed to measure the number of $\mathrm{Iba}^{+}, \mathrm{DCX}^{+}, \mathrm{SOX}^{+} / \mathrm{GFAP}^{+}$and $\mathrm{SOX}^{+} / \mathrm{GFAP}^{-}$ cells in the SGZ (at the junction between the granule cell layer and the hilus). Five animals per group were used for analysis.

According to the methods of Roughton et al. [58], stereological cell counting was performed for quantification of the total number of $\mathrm{BrdU}^{+}$cells in the $\mathrm{SGZ}, \mathrm{BrdU}^{+} / \mathrm{GFAP}^{+}$and $\mathrm{BrdU}^{+} / \mathrm{DCX}^{+}$cells in the GCL (plus SGZ). Serial $25 \mu \mathrm{m}$ sections through the rostrocaudal extent of the DG were selected at ten-section intervals for immunofluorescent staining and counterstaining with DAPI to mark nuclei in the DG. The total sum of the $\mathrm{BrdU}^{+}, \mathrm{BrdU}^{+} / \mathrm{GFAP}^{+}$or $\mathrm{BrdU}^{+} / \mathrm{DCX}^{+}$positive cells traced were multiplied by positive cells in the SGZ or GCL (plus SGZ) per section and series number to give the total number of $\mathrm{BrdU}^{+}, \mathrm{BrdU}^{+} / \mathrm{GFAP}^{+}$or $\mathrm{BrdU}^{+} / \mathrm{DCX}^{+}$ positive cells in the DG. Five animals per group were used for analysis.

\section{Cell alignment analysis}

We identified RGL progenitor cells as GFAPpositive cells that extend a single process from the SGZ toward the molecular layer. Cell alignment of BrdUlabeled RGLs was analyzed in order to evaluate the mode of cell division. Briefly, the vertical (asymmetrical) division mode is defined as daughter cells that are aligned vertically to the axis of the radial glial fiber, while horizontal (symmetrical) division mode describes daughter cells that are aligned horizontally to the axis of the radial glial fiber.

\section{Statistical analyses}

Statistical analyses were performed using SPSS 17.0 software (SPSS Inc., Chicago, IL, USA) to conduct twoway ANOVAs. Significant effects were evaluated with Tukey's post hoc tests or Bonferroni corrections. Data are presented as mean \pm SEM. Statistically significance was set at $p<0.05$.

\section{ACKNOWLEDGMENTS}

We thank Dr. Wei Sun in Biomedical Analysis Center, Third Military Medical University for technical support. 


\section{CONFLICTS OF INTEREST}

The authors have no competing financial interests.

\section{GRANT SUPPORT}

This study was supported by the National Nature Science Foundation of China (No. 81371197), the National Basic Research Program of China (973 Program) (2014CB541605), and Natural Science Foundation Project of CQ CSTC 2013jjB10028.

\section{REFERENCES}

1. Sobocki P, Jonsson B, Angst J and Rehnberg C. Cost of depression in Europe. J Ment Health Policy Econ. 2006; 9:87-98.

2. Sarkisova K and van Luijtelaar G. The WAG/Rij strain: a genetic animal model of absence epilepsy with comorbidity of depression. Prog Neuropsychopharmacol Biol Psychiatry. 2011; 35:854-876.

3. Massart R, Mongeau R and Lanfumey L. Beyond the monoaminergic hypothesis: neuroplasticity and epigenetic changes in a transgenic mouse model of depression. Philos Trans R Soc Lond B Biol Sci. 2012; 367:2485-2494.

4. Galecki P, Talarowska M, Anderson G, Berk M and Maes M. Mechanisms underlying neurocognitive dysfunctions in recurrent major depression. Med Sci Monit. 2015; 21:15351547.

5. Wang Z, Neylan TC, Mueller SG, Lenoci M, Truran D, Marmar CR, Weiner MW and Schuff N. Magnetic resonance imaging of hippocampal subfields in posttraumatic stress disorder. Arch Gen Psychiatry. 2010; 67:296-303

6. O'Connor JC, Lawson MA, Andre C, Moreau M, Lestage J, Castanon N, Kelley KW and Dantzer R. Lipopolysaccharide-induced depressive-like behavior is mediated by indoleamine 2,3-dioxygenase activation in mice. Mol Psychiatry. 2009; 14:511-522.

7. Brummelte S, Pawluski JL and Galea LA. High post-partum levels of corticosterone given to dams influence postnatal hippocampal cell proliferation and behavior of offspring: A model of post-partum stress and possible depression. Horm Behav. 2006; 50:370-382.

8. Lucassen PJ, Oomen CA, Naninck EF, Fitzsimons CP, van Dam AM, Czeh B and Korosi A. Regulation of Adult Neurogenesis and Plasticity by (Early) Stress, Glucocorticoids, and Inflammation. Cold Spring Harb Perspect Biol. 2015; 7:a021303.

9. Fava M, Johe K, Ereshefsky L, Gertsik LG, English BA, Bilello JA, Thurmond LM, Johnstone J, Dickerson BC, Makris N, Hoeppner BB, Flynn M, Mischoulon D, Kinrys $\mathrm{G}$ and Freeman MP. A Phase 1B, randomized, double blind, placebo controlled, multiple-dose escalation study of
NSI-189 phosphate, a neurogenic compound, in depressed patients. Mol Psychiatry. 2015.

10. Zhao C, Deng W and Gage FH. Mechanisms and functional implications of adult neurogenesis. Cell. 2008; 132:645660.

11. Suh H, Consiglio A, Ray J, Sawai T, D'Amour KA and Gage FH. In vivo fate analysis reveals the multipotent and self-renewal capacities of Sox $2+$ neural stem cells in the adult hippocampus. Cell Stem Cell. 2007; 1:515-528.

12. Hong $\mathrm{S}$ and Song MR. Signal transducer and activator of transcription-3 maintains the stemness of radial glia at midneurogenesis. J Neurosci. 2015; 35:1011-1023.

13. Barry DS, Pakan JM and McDermott KW. Radial glial cells: key organisers in CNS development. Int J Biochem Cell Biol. 2014; 46:76-79.

14. Gehm BD, McAndrews JM, Chien PY and Jameson JL. Resveratrol, a polyphenolic compound found in grapes and wine, is an agonist for the estrogen receptor. Proc Natl Acad Sci U S A. 1997; 94:14138-14143.

15. Saiko P, Szakmary A, Jaeger W and Szekeres T. Resveratrol and its analogs: defense against cancer, coronary disease and neurodegenerative maladies or just a fad? Mutat Res. 2008; 658:68-94.

16. Hauss F, Liu J, Michelucci A, Coowar D, Morga E, Heuschling P and Luu B. Dual bioactivity of resveratrol fatty alcohols: differentiation of neural stem cells and modulation of neuroinflammation. Bioorg Med Chem Lett. $2007 ; 17: 4218-4222$.

17. Xu L, Yang Y, Gao L, Zhao J, Cai Y, Huang J, Jing S, Bao X, Wang Y, Gao J, Xu H and Fan X. Protective effects of resveratrol on the inhibition of hippocampal neurogenesis induced by ethanol during early postnatal life. Biochim Biophys Acta. 2015; 1852:1298-1310.

18. Madhyastha S, Sekhar S and Rao G. Resveratrol improves postnatal hippocampal neurogenesis and brain derived neurotrophic factor in prenatally stressed rats. Int J Dev Neurosci. 2013; 31:580-585

19. Ali SH, Madhana RM, K VA, Kasala ER, Bodduluru LN, Pitta S, Mahareddy JR and Lahkar M. Resveratrol ameliorates depressive-like behavior in repeated corticosterone-induced depression in mice. Steroids. 2015; 101:37-42.

20. Ge JF, Peng L, Cheng JQ, Pan CX, Tang J, Chen FH and Li J. Antidepressant-like effect of resveratrol: involvement of antioxidant effect and peripheral regulation on HPA axis. Pharmacol Biochem Behav. 2013; 114-115:64-69.

21. Ge L, Liu L, Liu H, Liu S, Xue H, Wang X, Yuan L, Wang $\mathrm{Z}$ and Liu D. Resveratrol abrogates lipopolysaccharideinduced depressive-like behavior, neuroinflammatory response, and CREB/BDNF signaling in mice. Eur $\mathrm{J}$ Pharmacol. 2015; 768:49-57.

22. Yirmiya R. Endotoxin produces a depressive-like episode in rats. Brain Res. 1996; 711:163-174. 
23. Kurosawa N, Shimizu K and Seki K. The development of depression-like behavior is consolidated by IL-6-induced activation of locus coeruleus neurons and IL-1beta-induced elevated leptin levels in mice. Psychopharmacology (Berl). 2015; 233:1725-37.

24. Porsolt RD. Animal models of depression: utility for transgenic research. Rev Neurosci. 2000; 11:53-58.

25. Dunn AJ and Swiergiel AH. Effects of interleukin-1 and endotoxin in the forced swim and tail suspension tests in mice. Pharmacol Biochem Behav. 2005; 81:688-693.

26. Wall PM and Messier C. Ethological confirmatory factor analysis of anxiety-like behaviour in the murine elevated plus-maze. Behav Brain Res. 2000; 114:199-212.

27. Jacobs BL. Adult brain neurogenesis and depression. Brain Behav Immun. 2002; 16:602-609.

28. Hill AS, Sahay A and Hen R. Increasing Adult Hippocampal Neurogenesis is Sufficient to Reduce Anxiety and Depression-Like Behaviors. Neuropsychopharmacology. 2015; 40:2368-2378.

29. Kriegstein A, Noctor S and Martinez-Cerdeno V. Patterns of neural stem and progenitor cell division may underlie evolutionary cortical expansion. Nat Rev Neurosci. 2006; 7:883-890.

30. Namba T, Maekawa M, Yuasa S, Kohsaka S and Uchino S. The Alzheimer's disease drug memantine increases the number of radial glia-like progenitor cells in adult hippocampus. Glia. 2009; 57:1082-1090.

31. Guo L, Li S, Zhao Y, Qian P, Ji F, Qian L, Wu X and Qian G. Silencing Angiopoietin-Like Protein 4 (ANGPTL4) Protects Against Lipopolysaccharide-Induced Acute Lung Injury Via Regulating SIRT1/NF-kB Pathway. J Cell Physiol. 2015; 230:2390-2402.

32. Hatakeyama J, Bessho Y, Katoh K, Ookawara S, Fujioka M, Guillemot F and Kageyama R. Hes genes regulate size, shape and histogenesis of the nervous system by control of the timing of neural stem cell differentiation. Development. 2004; 131:5539-5550.

33. Monje ML, Toda $\mathrm{H}$ and Palmer TD. Inflammatory blockade restores adult hippocampal neurogenesis. Science. 2003; 302:1760-1765.

34. Littlefield AM, Setti SE, Priester C and Kohman RA. Voluntary exercise attenuates LPS-induced reductions in neurogenesis and increases microglia expression of a proneurogenic phenotype in aged mice. J Neuroinflammation. 2015; 12:138.

35. Gebara E, Sultan S, Kocher-Braissant J and Toni N. Adult hippocampal neurogenesis inversely correlates with microglia in conditions of voluntary running and aging. Front Neurosci. 2013; 7:145.

36. Sun D, Chen J, Bao X, Cai Y, Zhao J, Huang J, Huang W, Fan $\mathrm{X}$ and $\mathrm{Xu} \mathrm{H}$. Protection of Radial Glial-Like Cells in the Hippocampus of APP/PS1 Mice: a Novel Mechanism of Memantine in the Treatment of Alzheimer's Disease. Mol
Neurobiol. 2015; 52:464-477.

37. Bureau G, Longpre F and Martinoli MG. Resveratrol and quercetin, two natural polyphenols, reduce apoptotic neuronal cell death induced by neuroinflammation. J Neurosci Res. 2008; 86:403-410.

38. Kodali M, Parihar VK, Hattiangady B, Mishra V, Shuai B and Shetty AK. Resveratrol prevents age-related memory and mood dysfunction with increased hippocampal neurogenesis and microvasculature, and reduced glial activation. Sci Rep. 2015; 5:8075.

39. Torres-Perez M, Tellez-Ballesteros RI, Ortiz-Lopez L, Ichwan M, Vega-Rivera NM, Castro-Garcia M, GomezSanchez A, Kempermann G and Ramirez-Rodriguez GB. Resveratrol Enhances Neuroplastic Changes, Including Hippocampal Neurogenesis, and Memory in Balb/C Mice at Six Months of Age. PLoS One. 2015; 10:e0145687.

40. Park HR, Kong KH, Yu BP, Mattson MP and Lee J. Resveratrol inhibits the proliferation of neural progenitor cells and hippocampal neurogenesis. J Biol Chem. 2012; 287:42588-42600.

41. Hitoshi S, Maruta N, Higashi M, Kumar A, Kato N and Ikenaka K. Antidepressant drugs reverse the loss of adult neural stem cells following chronic stress. J Neurosci Res. 2007; 85:3574-3585.

42. Nokia MS, Lensu S, Ahtiainen JP, Johansson PP, Koch LG, Britton SL and Kainulainen H. Physical exercise increases adult hippocampal neurogenesis in male rats provided it is aerobic and sustained. J Physiol. 2016; 594:1855-1873.

43. Kapgal V, Prem N, Hegde P, Laxmi TR and Kutty BM. Long term exposure to combination paradigm of environmental enrichment, physical exercise and diet reverses the spatial memory deficits and restores hippocampal neurogenesis in ventral subicular lesioned rats. Neurobiol Learn Mem. 2016; 130:61-70.

44. Pfeuty B. A computational model for the coordination of neural progenitor self-renewal and differentiation through Hes1 dynamics. Development. 2015; 142:477-485.

45. Egger B, Gold KS and Brand AH. Notch regulates the switch from symmetric to asymmetric neural stem cell division in the Drosophila optic lobe. Development. 2010; 137:2981-2987.

46. Saharan S, Jhaveri DJ and Bartlett PF. SIRT1 regulates the neurogenic potential of neural precursors in the adult subventricular zone and hippocampus. J Neurosci Res. 2013; 91:642-659.

47. Cai Y, Xu L, Xu H and Fan X. SIRT1 and Neural Cell Fate Determination. Mol Neurobiol. 2015; 53:2815-2825.

48. Yang Y, Duan W, Li Y, Yan J, Yi W, Liang Z, Wang N, Yi $\mathrm{D}$ and Jin $\mathrm{Z}$. New role of silent information regulator 1 in cerebral ischemia. Neurobiol Aging. 2013; 34:2879-2888.

49. Lanzillotta A, Pignataro G, Branca C, Cuomo O, Sarnico I, Benarese M, Annunziato L, Spano P and Pizzi M. Targeted acetylation of NF-kappaB/RelA and histones by epigenetic 
drugs reduces post-ischemic brain injury in mice with an extended therapeutic window. Neurobiol Dis. 2013; 49:177189.

50. Koo JW, Russo SJ, Ferguson D, Nestler EJ and Duman RS. Nuclear factor-kappaB is a critical mediator of stressimpaired neurogenesis and depressive behavior. Proc Natl Acad Sci U S A. 2010; 107:2669-2674.

51. Cai N, Bigdeli TB, Kretzschmar W, Li Y, Liang J, Song L, Hu J, Li Q, Jin W, Hu Z, Wang G, Wang L, Qian P, et al. Sparse whole-genome sequencing identifies two loci for major depressive disorder. Nature. 2015; 523:588-591.

52. Di Liberto V, Makela J, Korhonen L, Olivieri M, Tselykh T, Malkia A, Do Thi H, Belluardo N, Lindholm D and Mudo G. Involvement of estrogen receptors in the resveratrolmediated increase in dopamine transporter in human dopaminergic neurons and in striatum of female mice. Neuropharmacology. 2012; 62:1011-1018.

53. Zonis S, Ljubimov VA, Mahgerefteh M, Pechnick RN, Wawrowsky K and Chesnokova V. p21Cip restrains hippocampal neurogenesis and protects neuronal progenitors from apoptosis during acute systemic inflammation. Hippocampus. 2013; 23:1383-1394.
54. Tian J, Zhang F, Cheng J, Guo S, Liu P and Wang H. Antidepressant-like activity of adhyperforin, a novel constituent of Hypericum perforatum L. Sci Rep. 2014; 4:5632.

55. Gu L, Liu YJ, Wang YB and Yi LT. Role for monoaminergic systems in the antidepressant-like effect of ethanol extracts from Hemerocallis citrina. J Ethnopharmacol. 2012; 139:780-787.

56. Jaehne EJ and Baune BT. Effects of chemokine receptor signalling on cognition-like, emotion-like and sociability behaviours of CCR6 and CCR7 knockout mice. Behav Brain Res. 2014; 261:31-39.

57. Xu P, Xu H, Tang X, Xu L, Wang Y, Guo L, Yang Z, Xing Y, Wu Y, Warner M, Gustafsson JA and Fan X. Liver X receptor beta is essential for the differentiation of radial glial cells to oligodendrocytes in the dorsal cortex. Mol Psychiatry. 2014; 19:947-957.

58. Roughton K, Andreasson U, Blomgren K and Kalm M. Lipopolysaccharide-induced inflammation aggravates irradiation-induced injury to the young mouse brain. Dev Neurosci. 2013; 35:406-415. 